\title{
LINGUAGENS, CÓDIGOS E SUAS TECNOLOGIAS: ALGUMAS REFLEXÕES E CONSIDERAÇÕES SOBRE O ENSINO POR ÁREA DO CONHECIMENTO
}

\author{
Hermes Talles dos Santos \\ Doutor em Linguística pelo Programa de Pós-Graduação em Linguística da Universidade Federal \\ de São Carlos e Coordenador do Curso de Licenciatura em Linguagens da Faculdade SESI-SP de \\ Educação.
}

\section{RESUMO}

A educação contemporânea demanda mudanças no currículo escolar para conseguir superar a fragmentação e integrar as disciplinas curriculares. No Brasil, para atender a tal demanda, os Parâmetros Curriculares Nacionais para o Ensino Médio organizam o currículo escolar por áreas do conhecimento. Embora pareça simples agrupar componentes curriculares, na prática, desenvolver um trabalho por agrupamento é complexo, pois cada forma de trabalho, disciplinar, multidisciplinar, interdisciplinar ou transdisciplinar, possui orientações e princípios teóricofilosóficos distintos; além disso, é preciso conciliar objetos de ensino historicamente trabalhados isoladamente. Nesse sentido, a partir de uma pesquisa qualitativa, documental e bibliográfica, refletimos sobre o objeto comum à área de Linguagens e suas tecnologias, com base em documentos oficiais, tecendo algumas considerações sobre o trabalho possível de ser desenvolvido.

Palavras-chave: Área de Linguagens, Ensino Médio, PCNEM, Multidisciplinar, Interdisciplinar, Transdisciplinar.

\section{LANGUAGE, CODES AND THEIR TECHNOLOGIES: SOME THOUGHTS AND CONSIDERATIONS BY KNOWLEDGE'S FIELD TEACHING}

\begin{abstract}
The contemporary context requires changes in school organization, going from fragmentation to integration of disciplines. Thus, in Brazil, the National Curriculum Parameters for high school structured disciplines by knowledge area. Although it may seem simple to group curriculum components, in practice, to develop a work by grouping is labored because each form of work possible - disciplinary, multidisciplinary, interdisciplinary or transdisciplinary - has different guidelines and theoretical-philosophical principles. Moreover, the curriculum components must connect teaching objects historically worked alone. Thus, through a qualitative research, documentary and bibliographical, we reflect on the common object to the area of Languages and their technologies, based on official documents, making some considerations about the possible work to be developed
\end{abstract}

Keywords: High school, Language, Disciplinary, Multidisciplinary, Interdisciplinary; Transdisciplinary.

\section{LENGUAJE, CÓDIGOS Y SUS TECNOLOGÍAS: ALGUNAS REFLEXIONES Y CONSIDERACIONES SOBRE LA ENSEÑANZA POR ÁREA DEL CONOCIMIENTO}

\footnotetext{
RESUMEN

La educación contemporánea requiere cambios en la organización de la escuela para poder pasar de la fragmentación a la interrelación de disciplinas. Así, en Brasil, los Parámetros Curriculares Nacionales para la escuela secundaria organizaron disciplinas por campo de conocimiento. Aunque parezca simple el trabajo a los componentes del plan de estudios de grupo, en la práctica, el desarrollo de una obra de agrupación es dificultosa debido a que cada forma de trabajo posible disciplinaria, multidisciplinaria, interdisciplinaria o transdisciplinaria - tiene diferentes directrices y principios teórico-filosóficos. Por otra parte, los componentes curriculares deben conectar objetos de enseñanza que historicamente son trabajan solo. Este ensayo, a partir de una investigación
} 
cualitativa, documental y bibliográfica, analiza los enfoques de desarrollo de trabajo de la agrupación y sus limitaciones y potencialidades. También presenta las intersecciones que permiten el desarrollo de un trabajo conjunto entre las disciplinas del campo: Linguagens, Códigos e suas Tecnologias.

Palabras clave: Educación Secundaria, Lenguajes, Disciplinaria, Multidisciplinaria, Interdisciplinaria, Transdisciplinaria.

Desencadeada na segunda metade do século XX e, indubitavelmente, fator influente da sociedade contemporânea, a III Revolução Industrial ou a Revolução TécnicoCientífico-Informacional promoveu social e historicamente mudanças significativas nas instituições sociais, na cultura e, principalmente, na vida e no quotidiano das pessoas.

$\mathrm{O}$ aspecto mais evidente dessa revolução, a nosso ver, é aquele concernente ao espaço-tempo. Outrora, qualquer interação interpessoal demandava tempo, e esse era maior ou menor a depender do espaço entre ou em que as pessoas se encontravam. Hoje, tal interação é praticamente imediata, não dependendo efetivamente do lugar ou da distância entre as pessoas. Evidentemente, esse aspecto ainda persiste no mundo sensível, porém o avanço e o desenvolvimento tecnológico propiciaram, de certo modo, reorganizá-lo, deixando de ser um fator determinantemente limitante ou complicador para a interação interpessoal.

Também oriunda dessa revolução, a rede mundial de internet, de um lado, propiciou a reformulação da relação espaço-tempo e, de outro, ampliou, de alguma forma, o acesso à informação produzida mundialmente. Nos dias atuais, a quantidade de informação disponível pela internet é muito maior do que nos anos finais do século XX, embora possamos e devamos discutir a dimensão qualitativa dessa ampliação. Se, de um lado, a reformulação e a ampliação foram promovidas por essa rede, por outro, a restrição por ela imposta está no fato de se ter, de algum modo, acesso a ela através de algum aparelho tecnológico e, concomitantemente, letramento suficiente para saber navegá-la.

Todas essas mudanças, indubitavelmente, influenciaram o contexto educacional, impactando, de alguma maneira, os conhecimentos, os docentes e suas práticas, os discentes, a organização escolar, o currículo e a didática, e, principalmente, o processo de ensino e aprendizagem. Essas mudanças demandam revisões, reorganizações ou reestruturações no ensino e na aprendizagem para contribuir satisfatoriamente com a formação de um estudante apto a exercer sua cidadania, consciente de seu papel social, e qualificado para o trabalho, nestes novos tempos (cf. art. $2^{\circ}$, BRASIL, 1996). 
Este trabalho propõe, assim, discutir como essas mudanças: por um lado, demandam mudanças no ensino contemporâneo, enfatizando possíveis explicações para o deslocamento do ensino disciplinar para o sistêmico; por outro, afetam a organização curricular da área de Linguagens, procurando caracterizá-la e refletir sobre como essa organização sistêmica potencializa ou restringe o processo de ensino e aprendizagem, partindo dos PCNEM (BRASIL, 1999a;1999b), PCN+ (BRASIL, 2002) e OCEM (BRASIL, 2006). Destarte, desenvolvemos uma pesquisa qualitativa, documental e bibliográfica (cf. MARCONI \& LAKATOS, 2010), investigando documentos oficiais, como as já citadas diferentes versões dos Parâmetros Curriculares Nacionais para o Ensino Médio, e publicações especializadas sobre propostas de trabalho ou de ensino, de algum modo, sistêmico.

Nesse sentido, apresentaremos inicialmente um breve percurso histórico, visando a contextualizar o trabalho dos componentes curriculares de maneira disciplinar e as orientações e suas possíveis razões, no cenário educacional brasileiro, para o desenvolvimento de um trabalho que visa à interação dos componentes curriculares que formam as áreas de conhecimento no Ensino Médio. Na sequência, conceituaremos e discutiremos brevemente as diferentes formas de trabalho - disciplinar, multidisciplinar, interdisciplinar e transdisciplinar -, ponderando sobre as possíveis potencialidades ou restrições de um trabalho sistêmico. Depois, intentamos compreender como os componentes curriculares da área de Linguagem se relacionam, a partir de seus objetos de estudo e de suas competências e habilidades (cf. BRASIL, 2017). Por fim, exporemos nossas considerações sobre a proposta de ensino por área do conhecimento.

Embora saibamos que os conceitos aqui discutidos já tenham sido amplamente explorados no nível acadêmico, por outro, devido a nossa experiência profissional, percebemos que tais conhecimentos ainda são dúbios no contexto da Educação Básica, principalmente quando os professores se propõem a desenvolver ou compartilham práticas de ensino que envolvem trabalhos ditos integradores (ou interdisciplinares). Ademais, apesar de haver suficiente discussão sobre a aplicação, reações, recepções, distorções ou revisões dos documentos governamentais que orientam o desenvolvimento dos componentes curriculares nas diferentes modalidades de ensino, não há, a nosso ver, suficiente divulgação disponível sobre o que seja trabalhar por áreas e, particularmente, sobre a área de Linguagens e suas tecnologias. 


\section{O surgimento da disciplinaridade e de suas contrapropostas}

Historicamente, o modelo disciplinar dos conhecimentos científicos está associado à Revolução Científica, ocorrida inicialmente no século XVI, e que tem suas raízes no pensamento de três cientistas, de tal época, exponenciais para o ocidente: Nicolau Copérnico, Galileu Galilei e Isaac Newton (cf. SOUSA SANTOS, 2006). Essa revolução, no plano da produção de conhecimentos, buscou desassociar a Ciência da Filosofia, por meio da proposição de elaboração de conhecimentos científicos de forma estruturada e prática, uma vez que, naquele período, a segunda exercia forte influência sobre a primeira.

Assim, em relação às contribuições de tais cientistas, vale ressaltar a proposta de Galileu Galilei, de cunho empirista, que, no nosso entender, conduziu as ciências e disciplinas científicas existentes na época à adoção de métodos, técnicas e produções de conhecimento disciplinares, por adotar uma metodologia científica em que o investigador precisava observar ou procurar em um fenômeno dados singulares que lhe permitissem a construção de generalizações, isto é, de leis e conhecimentos científicos (cf. ZYLBERSZTAJN, 1988). No fundo, a proposição de Galilei conduziu, a partir de então, cada vez mais, os cientistas à especialização de seus conhecimentos, métodos e técnicas, de forma que apurassem ou disciplinassem sua observação sobre singularidades dos fenômenos ou objetos analisados cientificamente.

A divisão das disciplinas científicas, no campo acadêmico, consolidou-se entre o começo do século XVIII e meados do século XIX, por um lado, baseada nos princípios científicos disciplinares da Revolução Científica, e, de outro, fortemente influenciada por noções de base naturalista, mecanicista e positivista (cf. SOUSA SANTOS, 2006), delimitando o campo de investigação, circunscrição do objeto de estudo e garantia da autonomia - e, de certa forma, isolamento - das áreas do conhecimento. Pautada sobre a tese de que os conhecimentos produzidos sem o rigor metodológico e em desacordo com os princípios epistemológicos da filosofia científica de cunho naturalista, mecanicista e positivista não seriam confiáveis, essa vertente científica, dita moderna, instaurou-se como forma privilegiada (e incentivada) de produção e divulgação de conhecimentos científicos, principalmente no meio acadêmico ocidental.

Tal revolução modificou no nível acadêmico a valoração do conhecimento. Conforme comenta Spink (1993), somente o conhecimento científico de cunho naturalista seria considerado como meio de gerar explicações capazes de esclarecer a verdade dos 
objetos de estudo. Assim, conhecimentos científicos, considerados formais, foram apreciados pela academia, enquanto conhecimentos de origem popular, sagrada ou filosófica foram considerados não formais, sendo academicamente desprestigiados.

Apropriando-se, de certo modo, dessas mudanças conceituais, o modelo escolar dito tradicional, com a estruturação organizacional e curricular, e alicerçada sobre a racionalidade, tem sua origem, na Europa, também no século XVI, que, como vimos, é o período em que ocorre o início da Revolução Científica (cf. TRINDADE \& MENEZES, 2009). Trata-se de uma escola burguesa, que precisa transmitir às crianças e aos jovens burgueses a erudição, os conhecimentos, os valores, os costumes e as crenças da burguesia (PILETTI \& PILETTI, 2010). Considerando que, devido às premissas renascentistas, a racionalidade era algo valorizado e relacionado ao modelo científico moderno, a escola, para cumprir sua missão social, seguindo o modelo metodológico científico vigorante, manteve os limites entre as fronteiras das disciplinas científicas em seu currículo, na tentativa de garantir a transmissão desses conhecimentos de forma condizente com sua produção conceitual na esfera acadêmica. Por isso, adotou-se, na esfera educacional, o modelo curricular disciplinar, em que se manteve, do ponto de vista didático, o isolamento entre os conhecimentos científicos.

Todavia, em meados do século XX, conforme palavras de Souza Santos (2006) houve a crise do paradigma científico dominante, que ocorreu, inicialmente, por conta das proposições científicas advindas da Teoria da Relatividade, consensualmente atribuída a Albert Einstein. A admissão do pressuposto de que não seria possível verificar empiricamente a simultaneidade de acontecimentos distantes, tal qual se faz com acontecimentos presentes no mesmo lugar, propiciou a interação e, até mesmo, integração de campos científicos usualmente isolados para explicar certos fenômenos da realidade sensível. Ou seja: as proposições teóricas, bem como as descobertas científicas propiciadas por Einstein geraram questionamentos às certezas e, por conseguinte, às verdades (cf. SPINK, 1993) das ciências modernas e de suas disciplinas, evidenciando que, nem sempre, o conhecimento isolado, isto é, disciplinar é capaz de explicar satisfatoriamente os acontecimentos do mundo sensível.

A partir daí, como pondera Coimbra (2000, p. 53), “[...] a dissecação do mundo e dos espíritos, impulsionada pela febre especializatória, chegou a tal ponto que se criou um mal-estar insuportável". Mal-estar, pois, por um lado, o contexto acadêmico, rigidamente pautado sobre os alicerces do modelo científico moderno, percebeu que muitos fatores 
influentes sobre determinado objeto analisado eram necessariamente desconsiderados ou recebiam pouca atenção no modelo científico exclusivamente vigorante até então; por outro, a crise desse modelo, propiciou o desenvolvimento de uma epistemologia científica em que os conhecimentos não precisavam ser rigidamente isolados, mas podiam interagir ou mesmo integrarem-se. Devido a isso, foram desenvolvidas outras metodologias científicas, que consideravam não apenas questões empíricas, mas também especulativas e experimentais, além de possibilitar a articulação de fatores naturais, sociais, históricos e culturais, possibilitando, assim, na análise, a consideração de um número maior de fatores que incidem sobre determinado objeto.

Tais transformações no plano científico resultaram também em mudanças sociais, culturais e em avanços tecnológicos. Historicamente, a partir da Revolução Industrial, a escola se consolidou como principal instituição de formação para o trabalho, preparando pessoas para a realização de atividades específicas. Nesse contexto, por um lado, a formação fragmentada, alienada e estanque (cf. PIRES, 1998) era perfeitamente adequada às demandas mecanicistas do mercado de trabalho e, por outro, atendia às expectativas do homem daquela época. No entanto, com a globalização dos povos e o desenvolvimento e o aprimoramento das tecnologias digitais, além do contexto marcado pela reorganização do capitalismo, em que "[...] os meios de produção querem agora trabalhadores mais qualificados, flexíveis, com nova base técnica e científica (constituída fundamentalmente pela informática), trabalhadores multifuncionais" (PIRES, 1998, p. 175), a formação das pessoas precisou ser sistêmica, preparando-as não exclusivamente para a realização de atividades específicas, mas capazes de se adequarem às diferentes demandas trabalhistas e tecnológicas com que têm socioculturalmente contato.

A respeito dessa formação sistêmica, é digno de nota o Projeto Pedagógico da Universidade Federal do ABC (2006). Conforme pondera tal documento, a Ciência, durante o século XX, percebeu as limitações e dificuldades do pensamento disciplinar e especializado para a compreensão de fenômenos mais amplos e que transcendiam os limites das disciplinas científicas, passando, em alguns casos, por elas desapercebidos. Por isso, segundo tal documento (UFABC, 2006, s.p),

$\mathrm{O}$ próprio século $\mathrm{XX}$, ao perceber essas dificuldades, gerou alguns novos conceitos que pretendem lidar com esta situação. O primeiro deles é a noção de sistema, que em poucas décadas se incorporou à visão do homem moderno. Ela permite abstrair a natureza física dos fenômenos, colocando-os num universo novo, abstrato, onde só interessa a relação entre as grandezas em jogo. A 
natureza sistêmica está na relação entre as coisas, e não nelas em si. Através do seu estudo, é possível compreender ao mesmo tempo diversas instâncias de uma mesma fenomenologia, ainda que sua manifestação se dê em contextos físicos bastante distintos.

Vale destacar que a visão sistêmica desloca o foco de análise do objeto ou do fenômeno para a relação que esse estabelece entre outros vetores, lembrando que isso não significa que ela desconsidere questões relativas ao próprio objeto ou fenômeno.

Consoante o documento em questão (UFABC, 2006), essa visão sistêmica modificou o próprio funcionamento da produção científica, demandando que cientistas de diferentes áreas trabalhem conjuntamente, isto é, incentivando o trabalho científico sistêmico. Além disso, o mesmo documento pontua que a visão sistêmica e a abordagem interdisciplinar apontam para uma nova forma de educação, em que modos e ritmos de apropriação do saber são possibilitados por uma estrutura disciplinar maleável e aberta.

A respeito da educação no século XXI, em certo ponto, o documento pontua (UFABC, 2006, s.p.) que

Enquanto a duração de uma carreira profissional no século XXI poderá se estender a 40 anos ou mais, a duração dos ciclos tecnológicos se reduz tipicamente a menos de cinco anos, podendo chegar a um ou dois anos em períodos de grande dinamismo. Se considerarmos um aluno que ingressa num curso tecnológico superior em 2006 para chegar ao mercado de trabalho em 2010, certamente a maior parte do conhecimento profissional que ele terá de aplicar entre 2010 e 2045-2050, quando se aposentar, ainda não existe hoje nem estará disponível durante o seu curso universitário. Assim sendo, o profissional terá que renovar o seu conhecimento várias vezes ao longo da carreira, se quiser manter a sua empregabilidade. Isso nos levará a um processo contínuo de renovação cognitiva, conhecido como educação continuada. Ainda não está muito claro o papel que a Universidade terá neste processo, mas, tendo em vista o tamanho da população envolvida - no limite, a totalidade dos profissionais em atividade, - é óbvio que a responsabilidade principal pela sua contínua reeducação deverá recair sobre os próprios profissionais e suas empresas, quando diretamente interessadas. Assim sendo, é função precípua da graduação preparar os futuros profissionais para conduzirem a sua educação continuada no futuro. Essa preparação deve privilegiar um conjunto de conhecimentos básicos e o desenvolvimento de atitudes de questionamento científico que, devidamente balizados pelo senso de responsabilidade social derivado da formação humanística, serão usados pelo futuro profissional como plataforma de educação e reeducação profissional ao longo da vida.

Apesar de ser um documento voltado para a educação superior, temos uma consideração importante, acerca da educação, como um todo, no século XXI: preparar pessoas responsáveis socialmente, isto é, cidadãos, capazes de conduzirem ao longo de sua vida sua própria formação educativa, de forma continuada. Para isso, teoricamente, um currículo composto por diversos componentes/disciplinas especializados, fragmentados, 
isolados e desarticulados, precisa ceder seu lugar a um currículo construído por disciplinas que interajam entre si, por meio de temas ou conhecimentos comuns, para a construção de pensamento crítico e formação integral (cf. PIRES, 1998). Essas mudanças implicam no desenvolvimento de pensamentos, estratégias e ações docentes diferentes e condizentes com o caráter interagente dos componentes curriculares.

Considerando, portanto, toda mudança histórico-social, cultural e econômica ocorrida durante século XX e início do século XXI, é razoável compreendermos que uma organização curricular no Ensino Médio, por áreas do conhecimento, seja uma tentativa de propiciar, conforme demarcam Domingues, Toschi \& Oliveira (2000, p. 67), “[...] uma formação que inclui flexibilidade funcional, criatividade, autonomia de decisões, capacidade de trabalhar em equipe, capacidade de exercer múltiplos papéis e executar diferentes tarefas, autonomia intelectual, pensamento crítico, capacidade de solucionar problemas". Trata-se, na verdade, de uma formação coerente com as premissas defendidas pelo MEC, nos anos finais da década de 90 - aliás, conforme demarcam Ferreti e Silva (2017), os postos estratégicos ocupados atualmente, durante o governo de Michel Temer, são justamente aqueles que já os ocuparam no governo de Fernando Henrique Cardoso. Sendo assim, é presumível que a Reforma do Ensino Médio (BRASIL, 2017) retome posições anteriormente adotadas.

A Lei 13.415, de 16 de fevereiro de 2.017 (BRASIL, 2017), que trata justamente da mais recente reforma, no campo educacional brasileiro, do Ensino Médio, dispõe que "os currículos do ensino médio deverão considerar a formação integral do aluno, de maneira a adotar um trabalho voltado para a construção de seu projeto de vida e para sua formação nos aspectos físicos, cognitivos e socioemocionais". O artigo oitavo da mesma lei (BRASIL, 2017) dispõe, em seus dois incisos, que ao final de todo o percurso educacional no Ensino Médio, o estudante deverá demonstrar "I - domínio dos princípios científicos e tecnológicos que presidem a produção moderna; e II - conhecimento das formas contemporâneas de linguagem." Trata-se, a nosso ver, de uma tentativa de adequar o currículo de tal segmento educacional às expectativas e às demandas contemporâneas.

Se, por um lado, os motivos teóricos e educacionais encontram-se respaldados na mencionada lei, por outro, tal reforma não orienta satisfatoriamente como essa organização por área do conhecimento efetivamente se organizará. De forma vaga, o quarto artigo da lei anteriormente citada (BRASIL, 2017) propõe que a organização, nas áreas do conhecimento, seja realizada por oferta de diferentes arranjos curriculares e de suas 
respectivas competências e habilidades, conforme os critérios estabelecidos por cada sistema de ensino.

Vale ainda citar que a mencionada lei, a nosso ver, é um contrassenso à proposta de trabalho sistêmico que até então vinha sendo defendido pelo MEC para o Ensino Médio e na mesma explicitado, uma vez que coloca como obrigatória a oferta contínua nos três anos desse nível de ensino apenas dos componentes curriculares de Língua Portuguesa e Matemática. Ora, no que concerne à Língua Portuguesa, ela compõe conjuntamente com outros componentes curriculares, como Artes, Língua Inglesa e Educação Física (cf. BRASIL, 2018), a área de Linguagens e suas tecnológicas, porém esses, diferentemente daquela, não precisam ser ofertados continuamente durante os três anos do Ensino Médio, logo a noção de área do conhecimento, no nosso entender, não se mantém e conflita a proposta de organização curricular defendida pela Lei 13.415/17.

Sabemos que não é esperado que uma lei já disponha sobre tal organização, porém, até o momento, valem, então, os documentos governamentais, como PCNEM (BRASIL, 1999a;1999b) e PCN+ (BRASIL, 2002) e OCEM (2006), produzidos nos primeiros decênios do século XXI, período em que há considerável mudança de concepção educacional nas orientações do Ministério da Educação. Recentemente o MEC publicou a Base Nacional Comum Curricular para o Ensino Médio - BNCCEM - (BRASIL, 2018), porém esse documento, embora se organize por áreas do conhecimento, em seu corpo não se ocupa em explicar como ocorreria a integração entre as unidades curriculares que as constituem, deixando mais uma vez em aberto essa discussão e, a nosso ver, não incentivando de fato o trabalho sistêmico na educação básica brasileira.

$\mathrm{Na}$ tentativa de apresentar a organização curricular integradora de forma mais delimitada e, assim, contribuirmos com o trabalho docente, consideramos oportuno retomar brevemente as formas possíveis de trabalho disciplinar e sistêmico, com base, principalmente em Japiassu (2006) e refletir como essa organização conforma uma área de ensino no processo de educação formal.

O trabalho disciplinar e sistêmico: limitante ou ampliador de conhecimentos?

O trabalho por áreas do conhecimento pretende tornar as fronteiras das disciplinas curriculares mais flexíveis e permeáveis. É preciso destacar que, quando se propõe trabalhar por área, não se pretende extinguir ou diluir as disciplinas já existentes no currículo escolar, embora alguns educadores aparentemente divirjam em relação a tal consideração. Morin (2000), por exemplo, assevera que a educação deve romper com o 
ensino fragmentado, em que a divisão disciplinar serviria para isolar os objetos de seu meio e suas partes de um todo, pois a realidade é global. Ao empregar o termo global, o mencionado teórico (MORIN, 2000, p. 43) destaca a interação e contextualização dos saberes necessários para a compreensão da realidade, afirmando ainda que "[...] a inteligência parcelada, compartimentada, mecanicista, disjuntiva e reducionista rompe o complexo do mundo em fragmentos disjuntos, fraciona os problemas, separa o que está unido, torna unidimensional o multidimensional."

Sem dúvidas, o posicionamento de Morin é pertinente e justificável. Entretanto, é preciso destacar que o autor não parece estar propondo ou defendendo o abandono total da disciplinaridade ou da especialização. Conforme Coimbra (2000, p. 66) destaca “[...] os especialistas serão sempre bem-vindos; e mais, serão sempre necessários. Chegando ao âmago das questões, num processo intradisciplinar, eles extrairão elementos valiosos para o tratamento interdisciplinar." Ou seja: o trabalho disciplinar, focado e isolado, também tem sua relevância e importância, principalmente no que tange a questões mais específicas, pois essas certamente precisam de explicações mais especializadas e aprofundadas. Assim, as disciplinas mesmo em um trabalho por área continuam a ter sua relevância dentro do currículo escolar.

Precisamos nos lembrar de que a visão sistêmica, que propõe a interação ou a integração entre as disciplinas do conhecimento, trabalha com foco, o qual pode estar distribuído entre o objeto de estudo e sua relação com os fatores que lhe influenciam. Nesse sentido, por um lado, não se justifica um trabalho puramente fragmentado, nem um totalmente integrado, que desconsidere singularidades; por outro, também se revela improcedente o temor de que o trabalho por área significaria a dispensa de especialistas para contratação de um único, mais global, ou, na educação, de um superprofessor (cf. JAPIASSU, 2006).

O que se objetiva com uma proposta de trabalho por área do conhecimento é justamente que haja maior interação entre os componentes curriculares, facilitando, assim, o desenvolvimento de saberes previstos no currículo, de forma contextualizada (cf. BRASIL, 1999). Na verdade, o que se postula, nesse tipo de trabalho, por um lado, é uma postura docente capaz de ultrapassar as fronteiras de sua disciplina, por meio de trabalhos conjuntos e de acordo com as contingências dos conteúdos curriculares e, por outro, estabelecer interconexões entre os conhecimentos, uma vez que "[...] as disciplinas são 'amarradas' pelos seus pontos de contatos e suas interfaces." (cf. COIMBRA, 2000, p. 64). 
Para compreendermos com mais detalhamento o trabalho por área do conhecimento, faz-nos necessário entender o que seja trabalhar os componentes de forma isolada ou inter-relacionada (sistêmica), bem como as diferentes maneiras de interação possível entre eles, ou seja, as distinções entre multi, inter ou transdisciplinaridade, pois, consoante Pires (1998, p. 176), “[...]a ideia de integração ou de totalidade que aparentemente perpassa estes conceitos tem referências teórico-filosóficos diferentes e inconciliáveis."

O trabalho (intra)disciplinar é o mais comum no cenário escolar. Esse tipo de trabalho consiste em desenvolver conteúdos e atividades de maneira isolada dentro do âmago de determinado saber (COIMBRA, 2000), isto é, sem interação com outros componentes curriculares. Trata-se de um trabalho adequado quando se tem por objetivo compreender determinado conteúdo do conhecimento de maneira aprofundada e especializada.

Coimbra (2000, p. 58) pondera que “[...] o intradisciplinar pode muito bem ser um passo consciente, de início limitado em si mesmo, que depois poderá abrir-se para outros campos do conhecimento." Nesse sentido, não seria repreensível o trabalho disciplinar, desde que seja possível ampliar os conhecimentos desenvolvidos por ele desenvolvidos. Para tanto, é preciso que haja postura dialógica (FREIRE, 1987) permissiva à busca por novas explicações, a partir de outros referenciais, ou ainda, consciente de seus limites.

O trabalho multidisciplinar consiste em um mesmo objeto ser tratado por diferentes abordagens, sem que, com isso, haja interação entre os componentes curriculares (cf. JAPIASSU, 2006). Em outras palavras: estabelece-se certa relação no estudo de dado objeto, mas cada disciplina parte e volta a seus próprios conhecimentos. Em relação à abordagem disciplinar, esta demonstra certo avanço no que tange à interação. Todavia, Pires (1998, p. 176) salienta que

A multidisciplinaridade parece esgotar-se nas tentativas de trabalho conjunto, pelos professores, entre disciplinas em que cada uma trata de temas comuns sob sua própria ótica, articulando, algumas vezes bibliografia, técnicas de ensino e procedimentos de avaliação. Poder-se-ia dizer que na multidisciplinaridade as pessoas [...] estudam perto mas não juntas. A ideia é de justaposição de disciplinas.

Muitas vezes, no contexto escolar, esse tipo de abordagem é confundido com o trabalho interdisciplinar. Entretanto, conforme se pode notar no excerto acima, as fronteiras dos componentes curriculares continuam a existir, não estabelecendo de fato 
integração intencional entre os saberes produzidos em cada componente curricular. Coimbra (2000, p. 57) assevera que "[...] a bem da realidade cotidiana, cada qual continua a ver e a tratar o seu objeto com os próprios critérios unidisciplinares, sem preocupar-se com qualquer outro que seja."

Para Japiassu (2006, p. 5), “[...] um agrupamento multidisciplinar já constitui uma equipe, devendo (para funcionar) obedecer às regras do trabalho coletivo", nesse sentido, a abordagem multidisciplinar seria uma maneira de se trabalhar por área, uma vez que o objeto do conhecimento passaria a ser estudado sob diferentes enfoques. Contudo, os limites das disciplinas continuam bem demarcados.

O trabalho interdisciplinar, para Japiassu (2006), se realiza nas fronteiras e nos pontos de contatos das disciplinas e, segundo Coimbra (2000, p. 51.), está intimamente relacionado à " “....] reformulação do saber, do ser e do fazer, à busca de uma síntese voltada para a reorganização da óikos - o mundo, nossa casa", pois propõe analisar e compreender determinado objeto (ou a realidade) de maneira abrangente. Para isso, é preciso que as disciplinas trabalhem conjuntamente seus pontos de convergência, procurando desenvolver explicações que atendam não apenas a uma parte, mas a todas as disciplinas envolvidas. Dito de outra forma, nessa abordagem, cada disciplina se vale de seus conhecimentos particulares, para, na articulação com outras disciplinas, construírem novos conhecimentos, capazes de responder às necessidades de todos os envolvidos.

Nesse trabalho, há obrigatoriamente a necessidade de, em certo sentido, integração entre os conhecimentos oriundos das diferentes disciplinas. O objeto de análise é compreendido por meio da síntese de diferentes explicações. Assim, as disciplinas continuam a existir, mas " [...] intencionalmente estabelecem nexos e vínculos entre si para alcançar um conhecimento diversificado e unificado." (COIMBRA, 2000, p. 58). Coimbra (2000) destaca que nessa abordagem é essencial a manutenção da identidade das disciplinas, conservando sua metodologia e seus limites, porém intercambiando suas hipóteses, elaborações e conclusões em busca de um entendimento comum.

A abordagem interdisciplinar, diferentemente da multidisciplinar, pressupõe que os objetos de ensino sejam compreendidos por meio da interação profícua dos conhecimentos de cada parte. Entretanto, o principal diferencial entre essas abordagens, a nosso ver, está na intencionalidade e metodologia. Na perspectiva multidisciplinar, o trabalho é conjunto, ou seja, ocorre ao mesmo tempo, entretanto, cada componente curricular, a partir de seu recorte científico, analisa e compreende isoladamente determinado objeto de ensino. $\mathrm{Na}$ 
orientação interdisciplinar o trabalho também é conjunto e concomitante, porém, a análise e a compreensão do objeto não é isolada, mas recíproca. Destarte, é preciso considerar o que são os conhecimentos de cada componente curricular, balizá-los e depois construir uma compreensão conjunta que atenda satisfatoriamente aos saberes das disciplinas envolvidas. Dessa forma, a intenção não está relacionada à análise de determinado enfoque disciplinar, mas à maior compreensão possível por meio de diferentes enfoques, sem que haja necessariamente o prevalecimento de um em detrimento de outro(s). Nas palavras de Japiassu (2006, p. 07) “a interdisciplinaridade desloca o centro em direção às fronteiras."

Com relação à abordagem transdisciplinar, Japiassu (2006, p. 7) explica-a como o nível em que se

[...] pode atravessar as disciplinas e visa à criação de um campo de conhecimento onde seja possível existir um novo paradigma ou um novo modo de coexistência e diálogo entre os filósofos e os cientistas, com os esquemas nocionais devendo circular da filosofia às ciências naturais e humanas, sem que haja nenhuma hierarquia entre esses diversos modos de problematização e experimentação.

Essa abordagem parece propor a integração total das disciplinas por meio da incorporação, com vistas à compreensão holística da realidade. Pires (1998, p. 176) pondera que “[...] a totalidade não se esgota na soma das partes, mas constitui-se, num outro patamar, na síntese histórica da realidade”. Nesse sentido, é preciso considerar o conhecimento em suas dimensões científica e histórica, isto é, em suas tensões sociopolítico-culturais.

Para alcançar o entendimento global almejado por tal abordagem, Japiassu (2006, p. 7) considera ser necessários cooperação, articulação, objetos e projetos comuns, e afirma que diferentemente da interdisciplinaridade, a transdisciplinaridade "[...] neutraliza a oposição centro-fronteira”, pois "[...] procura um recorte do saber distinto do disciplinar: por problemas, por exemplo [...]" e busca, no interior da cultura, um recorte disciplinar, tentando encontrar um paradigma comum, que possibilite a transversalidade disciplinar. Isso, segundo Coimbra (2006) possibilitaria um salto quali-quantitativo em relação aos conhecimentos e saberes capazes de serem produzidos por uma autossuperação técnicocientífica e humana.

Por ainda estar em discussão sua implementação, a transdisciplinaridade seria um anseio transformacional do campo científico-educacional (cf. COIMBRA, 2000; JAPIASSU, 2006; PIRES, 1998). Por isso Coimbra (2006, p. 59) afirma, “[...] resta [...] 
saber se, como a interdisciplinaridade, ela é um processo factível, e em que medida e modalidade o é."

Mediante apresentação das possibilidades de trabalho, destacamos que a implementação de um trabalho realmente por área do conhecimento requer do educador abertura a um processo cooperativo, planejado e compartilhado. Além disso, também requer conhecimento dos domínios e das potencialidades disciplinares, para conjuntamente com outro(s) educadores encontrar possíveis intersecções. A partir de então, analisar quais das abordagens podem ser mais produtivas, de acordo com intenção de sua prática e, principalmente, de sua disciplina curricular. Em outros termos, o trabalho por área depende da intencionalidade pedagógica do professor.

Destarte, a área de trabalho pode favorecer essa interação entre seus componentes curriculares, desde que haja minimamente na estrutura escolar, momentos em que os professores possam interagir com outros docentes de forma a refletir sobre quais abordagens seriam possíveis e como estabelecê-las no cotidiano escolar. É necessário, portanto, que haja momentos em que os professores possam se encontrar e planejar conjuntamente qual(is): o recorte de conteúdo, conhecimento e saber; ações de cada docente envolvido; materiais, tempo e espaços demandados; atividades práticas, teóricas e avaliativas serão realizadas por cada professor e pelos próprios estudantes envolvidos. Sem essa estrutura e considerando a precarização contínua das condições e do trabalho docente, acreditamos ser muito difícil que se possa desenvolver um trabalho verdadeiramente por área do saber, visto que, estamos considerando uma visão sistêmica, logo a abordagem não deve ser única ou exclusivamente disciplinar, mas, no mínimo, multidisciplinar e, satisfatoriamente, interdisciplinar.

Assim, por um lado, o trabalho sistêmico pode potencializar a interação e até mesmo a integração dos conhecimentos dos componentes curriculares para promover a formação integral discente, coerente com o contexto contemporâneo, desde que haja condições para essa realização. Por outro lado, consideramos que esse trabalho, intra-área, desprovido de tais condições e acrescido da ideia de um único professor, sem qualquer conhecimento disciplinar, isto é, específico dos componentes curriculares que formam a área poderá construir um único e grande componente curricular, com conhecimentos também disciplinares e não sistêmico. Dessa forma, o trabalho por área poderá ser distorcido e acomodar-se no comum hodierno da grade disciplinar da educação escolar, formando, na verdade, grandes componentes curriculares disciplinares. 
Portanto, vale ressaltar que o trabalho por área não menospreza nem desconsidera a necessidade da existência de professores especialistas. Isso não quer dizer que um professor não possa ser especialista em diferentes componentes curriculares, mas não é possível que ele seja especialista apenas em um componente e responsável por ministrar todos os demais. Destarte, nesse tipo de trabalho, todos os docentes são importantes, principalmente para garantir e ampliar, conforme as especificidades dos conhecimentos de suas disciplinas, o processo de ensino-aprendizagem dos estudantes.

Em suma, o deslocamento de um trabalho exclusivamente disciplinar para um sistêmico é algo, em parte, demandado pelo contexto sociocultural e histórico contemporâneo e, em parte, pela própria legislação educacional brasileira. Essa deslocação visa a promoção de uma formação integral que propicie ao estudante estabelecer relações entre conhecimentos, de forma a incentivar uma educação continuada, crítica e reflexiva, coerente com o exercício da cidadania e a formação para o trabalho no contexto contemporâneo.

$\mathrm{Na}$ sequência, discutimos a composição e a interação entre os componentes curriculares que forma a área de Linguagens, conforme os (BRASIL, 1999a;1999b), PCN+ (BRASIL, 2002) e OCEM (BRASIL, 2006), explorando pontos que possibilitem a articulação para o desenvolvimento do trabalho sistêmico na mencionada área do conhecimento.

\section{A Área de Linguagens}

De acordo com os PCNEM (BRASIL, 1999a;1999b) e os PCN+ (BRASIL, 2002), a área de Linguagens, Códigos e suas Tecnologias é composta pelas seguintes disciplinas: Língua Portuguesa, Língua Estrangeira Moderna, Arte, Educação Física e Informátical. No entanto, as Orientações Curriculares para o Ensino Médio (OCEM) (BRASIL, 2006) mencionam: Língua Portuguesa, Literatura, Língua Estrangeira Moderna - Espanhol, Arte e Educação Física. Estranhamente, as disciplinas de Língua Inglesa e Informática não são citadas pelas OCEM e, além disso, são introduzidas duas novas disciplinas: Literatura $e$ Espanhol. A BNCCEM (BRASIL, 2018), por sua vez, reorganiza tal área, nomeando-a por Linguagens e suas tecnologias, e restringindo sua composição à: Língua Portuguesa, Artes, Língua Inglesa e Educação Física.

\footnotetext{
${ }^{1}$ Não desenvolveremos aqui reflexões sobre o componente curricular de Informática, por nosso desconhecimento sobre os conteúdos de ensino por ele trabalhados na escola de Educação Básica.
} 
Incongruências à parte, os PCN+ (BRASIL, 2002, p. 26) justificam a reunião de tais disciplinas por meio do eixo Representação e Comunicação, explicitando que, para a área de Linguagens, “[...] o grande objeto de estudo são as várias linguagens e os códigos por elas estruturados, nas manifestações particulares que delas se valem (textos) para estabelecer diferentes formas de comunicação”, perpassando “[...] da compreensão e do uso particular das linguagens específicas empregadas nas práticas de cada disciplina à compreensão e à análise da faculdade humana de construir e utilizar a linguagem substrato comum".

Tais documentos oficiais (BRASIL, 1999b; 2002) não definem objetivamente o que seria o eixo Representação e Comunicação. Há alguns indícios. Os PCNEM (BRASIL, 1999b, p. 19) consideram a linguagem

[...] como capacidade humana de articular significados coletivos em sistemas arbitrários de representação, que são compartilhados e que variam de acordo com as necessidades e experiências da vida em sociedade. A principal razão de qualquer ato de linguagem é a produção de sentido.

Podemos, assim, falar em linguagens que se inter-relacionam nas práticas sociais e na história, fazendo com que a circulação de sentidos produza formas sensoriais e cognitivas diferenciadas. Isso envolve a apropriação demonstrada pelo uso e pela compreensão de sistemas simbólicos sustentados sobre diferentes suportes e de seus instrumentos como instrumentos de organização cognitiva da realidade e de sua comunicação. [...]

O excerto apresenta, a nosso ver, hibridização de concepções linguísticas distintas: linguagem como instrumento de comunicação e linguagem como processo/meio de interação (cf. GERALDI, 1984; NEDER, 1993; TRAVAGLIA, 2009). Porém, a concepção adotada em tais documentos tende a ser preponderantemente a segundo, pois compreende a linguagem como inter-relacionada ao uso, situado em práticas sociais e históricas, e como produtora de sentidos. Entretanto, devido às escolhas lexicais, pode também conduzir à noção de que se trata da concepção de linguagem enquanto Instrumento de Comunicação, principalmente se nos detivermos nas primeiras linhas do primeiro parágrafo transcrito acima, que emprega os termos coletivos, sistemas arbitrários de representação, ato de linguagem e, no parágrafo subsequente, de outros termos: formas, sistema simbólico, suporte e instrumento. Considerando que nosso leitor não é exclusivamente proveniente da área de Letras, é preciso que demarquemos a diferença entre tais concepções de linguagem.

A concepção de linguagem enquanto Instrumento de Comunicação considera, grosso modo, que a comunicação se realiza por meio de códigos (signos), utilizados de 
maneira preestabelecida e convencionada, desde que conhecidos e compartilhados pelos interagentes, emissor e receptor (cf. GERALDI, 1984). Logo, o ato comunicativo ocorreria quando alguém (emissor), querendo expressar-se, organizaria os códigos linguísticos² disponíveis e conhecidos e os transmitiria a outra pessoa (receptor). Esta, por sua vez, necessitaria apenas decodificar o que lhe fora transmitido para compreender a mensagem pretendida pelo emissor. A ênfase está sempre no indivíduo que ou organiza ou recebe os códigos que instauram a comunicação. Podemos considerar que a linguagem, para essa concepção, seja compreendida como algo, de certa forma, mecânico e controlável, pois, caso a mensagem do emissor não seja compreendida pelo receptor, algo inadvertido acometeu a mensagem comunicada durante o processo de sua transmissão. Nesse sentido, para que seja passível de análise e compreensão, a comunicação é entendida como um produto social concluído. Também vale destacar que nessa concepção, a língua é tida como parte da linguagem, isto é, algo maior àquela. Assim, uma faz parte da outra, mas não são idênticas nem se organizam ou funcionam de mesma maneira.

Embora possua noções interessantes, tal concepção está muito mais voltada à compreensão do sistema e das estruturas linguísticas, isto é, centra-se mais na análise do sistema que possibilita a comunicação, o que justifica seu apreço pelas formas e as relações por elas estabelecidas. Como pondera Franchi (1988, p. 25), nessa concepção, a linguagem seria reduzida a "[...] um papel de ferramenta social, a limitar-se pela observação de sua face exterior, puramente instrumental." Ferramenta social, porque serviria simplesmente para estabelecer comunicação entre pessoas; observação de sua face exterior, por ser tomado para análise enquanto um produto comunicativo finalizado; e instrumento, por servir como veículo transmissivo de mensagens.

A concepção da linguagem como Processo de Interação não desconsidera o fato de que a linguagem precisa de um arranjo organizacional para viabilizar a comunicação, entretanto, esse fato não condiciona nem se pressupõe à comunicação. Não há separação entre língua e linguagem. Ambas se organizam em construções linguísticas dinâmicas que, de forma tensiva, ao serem empregadas são organizadas e se organizam reciprocamente. Desse modo, a linguagem é compreendida como prática social, em processo contínuo de construção, permeada e perpassada por questões do contexto social e, concomitantemente, histórico, que também influem em sua realização.

\footnotetext{
${ }^{2}$ Ponderamos que, neste texto, empregamos o termo linguístico não se referindo apenas à língua, mas, em seu sentido amplo, à linguagem.
} 
Podemos considerar que para essa concepção, a centralidade está no jogo dialético ou tensivo que propulsiona a interação, por isso a linguagem não é um mero instrumento nem se resume à comunicação. Ultrapassa os limites instrumentais e comunicativos. Ao empregar a linguagem, agimos sobre alguém, despertando respostas ou atitudes sobre as quais não temos muito controle ou não podemos determinar. Sendo assim, a linguagem não pode ser compreendida como um produto concluído, que deve ser decodificado, mas como algo dinâmico, que se atualiza, produzindo sentidos diferentes, a cada situação comunicativa.

Ainda para esta concepção, os signos são ideológicos. Dessa forma, conforme pontua Franchi (1988, p. 31),

[...] não há nada imanente na linguagem, salvo sua força criadora e constitutiva [...]. Não há nada universal, salvo o processo [...] A linguagem, pois, não é um dado ou resultado; mas um trabalho que 'dá forma' ao conteúdo variável de nossas experiências, trabalho de construção, de retificação do 'vivido', que ao mesmo tempo constitui o sistema simbólico mediante o qual se opera sobre a realidade e constitui a realidade como um sistema de referências em que aquele se torna significativo.

A nosso ver, enquanto sistema simbólico, a linguagem é semiológica, isto é, conjunto de significações, dependente de contexto social e cultural.

Procuramos, pois, para um trabalho por área, não restringir linguagem à língua, conforme a primeira concepção linguística apresentada. De acordo com Lyons (2011), há duas possibilidades para a compreensão do termo linguagem. A primeira, em seu sentido mais amplo, pode compreender signos verbais e não verbais. A segunda, por sua vez, compreenderia apenas o verbal. Na primeira, teríamos uma visão de linguagem, da qual a língua faz parte. Na segunda, linguagem como praticamente sinônimo de língua.

Na nossa visão, o elo entre as disciplinas que compõem a área do conhecimento em questão é a linguagem. As línguas (Português, Inglês e Espanhol) se orientam mais para o trabalho com o signo verbal; as linguagens (Arte, Educação Física e Informática) para os signos não verbais. Todas elas trabalham com produção de sentidos semiológicos, por meio de organizações linguísticas em dadas situações comunicativas, o que envolve, consequentemente, questões ideológicas e de poder.

Considerando que atualmente vivemos em uma sociedade majoritariamente com textos multimodais (cf. DIONÍSIO, 2011), isto é, em que verbal e não verbal ocorrem 
simultaneamente, o desenvolvimento de atividades de leitura e compreensão textuais ${ }^{3}$ se tornam mais significativas se forem exploradas não só em sua dimensão linguísticodiscursiva, mas também artística; não só em sua forma verbal, mas também em sua estética.

Se, de um lado, a base para a articulação entre os componentes curriculares da área de Linguagens é a própria linguagem, de outro, como pontua a recente Reforma do Ensino Médio (BRASIL, 2017), a organização intra-área deve ocorrer também com base nas competências e habilidades a serem desenvolvidas nessa área.

Em consulta ao site do INEP (s/d), responsável pela aplicação do ENEM e ENCCEJA, avaliações em larga escala, justamente sobre conhecimentos previstos para o Ensino Médio, encontramos uma matriz de referência com cinco eixos cognitivos, gerais a todas as áreas, nove competências, nas quais são distribuídas 30 habilidades, específicas para a área de Linguagens. As competências articulam-se, em parte, especificamente a cada componente curricular da área, exceto Informática, e, em parte, inter-relacionando dois ou mais componentes, inclusive conhecimentos mais próximos à Informática, como as Tecnologias da Informação e Comunicação (TICs). Vejamos alguns exemplos, todos da Matriz de Referência do ENEM ou do ENCCEJA (s/d, s/p):

- específico de um componente - Educação Física:

Competência de área 3 - Compreender e usar a linguagem corporal como relevante para a própria vida, integradora social e formadora da identidade.

H9 - Reconhecer as manifestações corporais de movimento como originárias de necessidades cotidianas de um grupo social.

H10 - Reconhecer a necessidade de transformação de hábitos corporais em função das necessidades cinestésicas.

H11 - Reconhecer a linguagem corporal como meio de interação social, considerando os limites de desempenho e as alternativas de adaptação para diferentes indivíduos.

- comuns a mais de um componente - Línguas Inglesa e Espanhola:

“Competência de área 2 - Conhecer e usar língua(s) estrangeira(s) moderna(s) como instrumento de acesso a informações e a outras culturas e grupos sociais. H5 - Associar vocábulos e expressões de um texto em LEM ao seu tema.

H6 - Utilizar os conhecimentos da LEM e de seus mecanismos como meio de ampliar as possibilidades de acesso a informações, tecnologias e culturas. [...]

- comuns a mais de um componente - incluindo Informática:

\footnotetext{
${ }^{3}$ Baseando-se nos estudos semióticos de Greimas (1966), consideramos texto como o conjunto de signos verbais e não verbais, ou corpus, estruturalmente organizado (sintaxe) e capaz de produzir sentidos (semântica). Destarte, ao empregarmos tal termo, não nos restringimos apenas ao verbal, mas também ao não verbal. Por isso, entendemos que obras artísticas (músicas, quadras, pinturas, danças...) também são textos, por ser corpora, organizado e significante.
} 
Competência de área 9 - Entender os princípios, a natureza, a função e o impacto das tecnologias da comunicação e da informação na sua vida pessoal e social, no desenvolvimento do conhecimento, associando-o aos conhecimentos científicos, às linguagens que lhes dão suporte, às demais tecnologias, aos processos de produção e aos problemas que se propõem solucionar.

H28 - Reconhecer a função e o impacto social das diferentes tecnologias da comunicação e informação.

H29 - Identificar pela análise de suas linguagens, as tecnologias da comunicação e informação.

H30 - Relacionar as tecnologias de comunicação e informação ao desenvolvimento das sociedades e ao conhecimento que elas produzem

Destarte, considerando que nossa sociedade está, de certa forma, inserida em um mundo globalizado, a ocorrência conjunta da língua materna e de estrangeira(s) vem se tornando algo comum. Inúmeros textos, em sua maioria publicitários, veiculados por revistas, jornais ou outdoors articulam expressões em língua materna e estrangeira. Além disso, músicas, filmes, séries, programas... chegam a nossos lares por meio de canais de comunicação como televisão, internet e rádio em suas línguas originais. Não há assim fronteiras rígidas entre as línguas. Desse modo, um trabalho entre as disciplinas linguísticas, visando ao efeito de sentido produzido por essa junção linguística, além de destacar, dos próprios textos escolhidos para análise, a função comunicativa de dadas expressões, ampliando para o trabalho com a produção de textos semelhantes, pode ser proveitoso e interessante, principalmente em um contexto escolar, cujas línguas estrangeiras contam apenas com uma ou duas aulas semanais, com menos de uma hora. Esta talvez seja uma alternativa para que tais disciplinas consigam superar o pouco tempo que o currículo escolar lhes assegura.

No que tange às disciplinas de Arte e Educação Física, um trabalho por área pode ser desenvolvido a partir da noção do que seja dança para cada um desses componentes curriculares, refletindo sobre como o movimento é trabalhadas estética, artística e esportivamente; ou pode também trabalhar o corpo humano, discutindo como a cultura de um grupo social ou de um processo histórico produz representações artísticas ou padrões de beleza diferenciados. É preciso demarcar que essas são disciplinas em que a comunicação ocorre por meio da linguagem não verbal. Logo, conscientizar os estudantes de que, embora nossa sociedade seja grafocêntrica, há outras manifestações linguísticas válidas e reconhecidas, é papel da área de Linguagens como um todo, mas principalmente dessas disciplinas. 
Além disso, a tecnologia disponível em nosso contexto sociocultural também possibilita o desenvolvimento de atividades que analisem e produzam textos envolvendo a oralidade, em língua materna ou estrangeira, com textos não verbais, como música e coreografia, possibilitando, assim, a discussão sobre a articulação entre diferentes linguagens e como ela impacta na produção, na circulação e na estética dos textos e de seus sentidos.

As abordagens dos conteúdos, quais articulações e como elas ocorrerão, na verdade, dependem da intencionalidade dos professores, como já afirmamos anteriormente. Assim, de acordo com o currículo previsto, os professores podem estabelecer relações entre os conteúdos de seus componentes curriculares com aqueles previstos nos outros. Novamente reiteramos que para isso se efetivar é preciso que haja a reserva de tempo, no próprio calendário escolar, para que os professores possam juntos discutir e planejar seus processos de ensino e aprendizagem.

Em suma, a linguagem é o epicentro da área de Linguagens ${ }^{4}$. A ação linguística necessariamente se faz pela produção de significados, que estão intimamente relacionados às dimensões social e histórica. Nesse sentido, podemos considerar que toda interação comunicativa está envolta por discurso, aqui compreendido como ação ideológica, contextualizada socialmente e produtora de sentidos. Por isso, segundo Brandão (s/d, p. 2), "não há discurso neutro, todo discurso produz sentidos que expressam as posições sociais, culturais, ideológicas dos sujeitos da linguagem". Dessa forma, é necessário analisar sua organização; também é preciso situá-lo enquanto manifestação sociocultural, entendendo-o como uma ocorrência histórica e ideológica; também se faz necessário incentivar a produção comunicativa, não apenas de textos verbais, como faz majoritariamente a escola na atualidade, mas de textos não verbais, vistos como um processo discursivo e interacional. Nesse aspecto, em lugar de apenas analisar e admirar as produções textuais (e artísticas), ou mesmo apenas assistir a competições esportivas, devemos compreendê-las e, conforme a situação comunicativa, de forma consciente, saber os discursos que mobilizam e que os perpassam.

\footnotetext{
${ }^{4}$ É preciso demarcar que o componente curricular de Educação Física possui entre seus conteúdos de ensino uma parte mais voltada ao condicionamento físico e à prática esportiva. Isso não inviabiliza que o docente empregue tal parte também associada à produção de sentidos, visto que alguns esportes são culturalmente mais voltados ao público masculino, enquanto outros ao feminino, ou que alguns esportes são típicos de alguns países e povos. Há nessa parte também o seguimento de regras e o desenvolvimento de ações para que estabeleça efetivamente as atividades esportivas, que, à primeira vista, podem não construir comunicação, mas que de acordo com a intencionalidade do professor responsável por tal componente ou por outro(s), da própria área, pode vir a contribuir com questões de uso ou produção de significados.
} 
Tomando, portanto, a linguagem como o epicentro, os professores, de acordo com os conhecimentos de seu componente curricular, já têm uma relação estabelecida entre seus conteúdos de ensino. Isso faz com que não se tenha apenas objetos de ensino isolados em um componente, mas uma abordagem inter-relacional de tais objetos, evidenciando, assim, uma visão sistêmica do processo de ensino e aprendizagem. Esse deslocamento favorece o trabalho da área e orienta para um trabalho qualitativo, transformando os estudantes de meros analistas a produtores textuais. Nesse ponto, em consonância com as considerações das OCEM (BRASIL, 2006), há a promoção de práticas sociais e históricas com intuito de que os estudantes se apropriem e compreendam os usos e as atividades de linguagem.

Tomando também as Matrizes de Referência (INEP, s/d) e considerando a premissa de que competências e habilidades dos componentes curriculares da área devem orientar a organização dos trabalhos na área de Linguagens, temos maior delimitação das possibilidades de desenvolvimento de trabalhos, que vão desde abordagens disciplinares, até sistêmicas. Mais uma vez, ressaltamos que os responsáveis por essa organização são os professores da área de conhecimento de Linguagens, que devem planejar e desenvolver o trabalho sistêmico conforme suas intencionalidades pedagógicas. Contudo, o trabalho com a linguagem deve ser associado às mencionadas matrizes, para a promoção de um trabalho sistêmico ou disciplinar de forma mais coerente com as orientações oficiais.

\section{Algumas Considerações}

O trabalho por área do conhecimento é demanda da educação contemporânea, que precisa formar agentes sociais com uma visão sistêmica e não apenas disciplinar, propiciando-lhes, assim, autonomia e criticidade, qualidades relevantes para a vida profissional e social no século XXI. Embora seja uma demanda, o ensino disciplinar ainda encontra espaço e força no ambiente escolar brasileiro, por conta do aspecto histórico, em que tal modelo esteve associado à estruturação curricular dos componentes de ensino e aprendizagem e à própria organização escolar.

Em parte, há também o receio de que o trabalho por área esteja atrelado à dispensa de professores para contratação de um único superprofessor, capaz de atuar profissionalmente em todas as disciplinas do agrupamento. Esse temor, aliado ao desconhecimento de como realizar um trabalho por área, gera inseguranças nos docentes quanto às mudanças organizativas do currículo escolar. Como vimos, trabalhar por área 
não prevê necessariamente a dispensa dos professores, uma vez que as especificidades referentes a cada disciplina precisam de especialistas para desenvolvê-las em sala de aula. Além disso, o trabalho sistêmico, em que os componentes curriculares estão em constante interação, necessita de conhecimentos especializados para que os componentes curriculares contribuam com a compreensão dos fenômenos ou objetos de estudos de forma relacional, por meio da promoção da interação entre conhecimentos basilarmente disciplinares.

Contudo, para se trabalhar por área do conhecimento é preciso encontrar ou estabelecer pontos de convergência entre os conhecimentos elencados para o ensino. Nesse sentido, é necessário que haja uma estrutura nas escolas que possibilitem espaços para que os professores possam, conjuntamente com seus pares de área, elaborar seus planos de ensino, considerando a intencionalidade pedagógica dos docentes e também as competências e as habilidades da área (cf. BRASIL, 2017). O planejamento conjunto, por sua vez, precisa ter como norte o desenvolvimento de um trabalho sistêmico, numa perspectiva que pode ser multi, inter, ou até mesmo, transdiciplinar, desde que seja algo intencional dos docentes envolvidos.

Sem esse espaço na estrutura escolar não adianta a mudança na organização dos componentes por área, nem a cobrança das gestões escolares, nem a adoção de materiais didáticos com uma visão sistêmica do ensino - se é que esses materiais existam. É preciso lembrar que os professores são especialistas em sua formação inicial e, dessa forma, atuam, com segurança, dentro dos limites de seus componentes curriculares, logo, no máximo, conseguirão desenvolver uma proposta multidisciplinar, mas não interdisciplinar. Se para uma abordagem interdisciplinar é preciso que haja interação entre os conhecimentos, primeiramente é preciso que os responsáveis por desenvolvê-la interajam, encontrando e planejando os pontos de convergência entre os conhecimentos previstos para o ensino.

No caso da área de Linguagens, Códigos e suas Tecnologias, o que justifica, a nosso ver, o agrupamento dos componentes curriculares que a compõe pelos PCNEM (BRASIL, 1999a; 1999b), PCN+ (BRASIL, 2002) e BNCCEM (BRASIL, 2018) é a linguagem. Nesse sentido, cada professor da área precisa, previamente, analisar e compreender como seu componente curricular compreende e utiliza-se da linguagem e como produzem discursos sociais, considerando também as Matrizes Curriculares do ENEM e ENCCEJA (INEP, s/d). A partir daí, cremos que o estabelecimento de pontos convergentes intra-área ficará mais evidente, conduzindo, assim, para que as especificidades de cada componente curricular contribuam com a análise, compreensão e 
produção textual, de forma sistêmica. Com isso, na escola, teremos o desenvolvimento do estudante enquanto agente social por meio das diferentes linguagens.

Apresentamos também, nesse trabalho, algumas sugestões, bastante embrionárias, para a interação entre algumas disciplinas da área de Linguagens. Destacamos que elas foram feitas apenas com intuito de demonstrar algumas possibilidades. Contudo, reforçamos novamente que o principal ator para que essa interação ocorra nas escolas são os professores, lembrando que por se tratar de algo relativamente recente, essa proposta possui ainda seus desafios, que precisam ser assumidos, de forma que as experiências possam contribuir como embasamento e sugestões de caminhos para o desenvolvimento satisfatório de um trabalho por área do conhecimento. Além disso, é preciso também que os docentes reivindiquem nas estruturas escolares condições favoráveis para o desenvolvimento de tais propostas.

\section{Referências Bibliográficas}

BRANDÃO, H. H. N. Analisando o discurso. Museu da Língua Portuguesa: Estação da Luz. São Paulo: Museu da Língua Portuguesa. s/d. Disponível em: http://www.museulinguaportuguesa.org.br/files/mlp/texto_1.pdf, acessado em janeiro de 2014.

BRASIL. Ministério da Educação. Secretaria de Educação Básica. Base Nacional Comum Curricular: Ensino Médio. Brasília, MEC, 2018.

LDB. Lei 9394/96 - Lei de Diretrizes e Bases da Educação Nacional. Disponível em < www.planalto.gov.br > . Acesso em 20 de maio de 2018.

Lei $\mathbf{n}^{\mathbf{0}}$ 13.415, de 16 de fevereiro de 2017. Altera as Leis nos 9.394, de 20 de dezembro de 1996 dá outras providências. Disponível em < www.planalto.gov.br >. Acesso em 14 de abril de 2018.

Parâmetros curriculares nacionais: ensino médio, v.I. Brasília: Semtec, 1999a.

Parâmetros curriculares nacionais: ensino médio, v.II. Brasília: Semtec, 1999b.

PCN+ Ensino Médio: orientações educacionais complementares aos Parâmetros Curriculares Nacionais - Linguagens, Códigos e suas Tecnologias. Brasília: Semtec, 2002.

Orientações Curriculares para o Ensino Médio, v.I. Brasília: MEC/SEB, 2006.

COIMBRA, J. de A. A. Considerações sobre a Interdisciplinaridade, in: PHILLIPI, Jr. A.; TUCCI, C. E. M.; HOGAN, D. J. \& NAVEGANTES, R. Interdisciplinaridade em Ciências Ambientais. São Paulo: Signus, 2000. p. 52-70. 
DIONISIO, A. P. Gêneros textuais e multimodalidade, in: KARWOSKI, A. M.; GAYDECZKA, B.; BRITO, K. S. Gêneros textuais: reflexão e ensino. São Paulo: Parábola Editorial, 2011.

DOMINGUES, J. J.; TOSCHI, N. S. \& OLIVEIRA, J. F. de. A reforma do Ensino Médio: A nova formulação curricular e a realidade da escola pública. Educação e Sociedade, Campinas, v. 21, n. 70, p. 63-79, Abr. 2000.

FERRETI, C. J. \& SILVA, M. R. da. Reforma do Ensino Médio no contexto da medida provisória n ${ }^{\circ}$ 746/2016: estado, currículo e disputas por hegemonia. Educação e Sociedade, Campinas, v. 38, n. 139, p. 385-404, Jun. 2017

FRANCHI, C. Linguagem: Atividade Constitutiva. Caderno de Estudos Linguísticos, Campinas, n.22, p. 9-39, jan./jun. 1992.

FREIRE, P. Pedagogia do Oprimido. Rio de Janeiro: Paz e Terra, 1987.

GERALDI, J. W. O texto na sala de aula. Cascavel: Asseoeste, 1984.

GREIMAS, A. J. Semântica estrutural: pesquisa de método. São Paulo: Cultrix,1966.

INEP. Instituto Nacional de Estudos e Pesquisas Educacionais. Anísio Teixeira. Ministério da Educação. Matrizes de Referência do ENEM e do ENCCEJA. s/d. Disponível em: http://portal.inep.gov.br/web/guest/educacao-basica. Acesso em 25 de maio de 2018.

JAPIASSU, H. O Espírito Interdisciplinar. Cadernos Ebape, Rio de Janeiro, v. 4, n. 3, out. 2006.

LYONS, J. Linguagem, in: Janeiro: LTC, 2011. p.1-23.

. Lingua(gem) e Linguística: uma introdução. Rio de

MARCONI, M. de A. \& LAKATOS, E. M. Fundamentos da metodologia científica. São Paulo: Atlas, 2010.

MORIN, E. Os Sete Saberes necessários à Educação do Futuro. São Paulo: Cortez, 2000.

NEDER, M. L. C. Concepção de linguagem e ensino de língua portuguesa. Polifonia, Cuiabá, v. 1, n. 0, p.71-89, 1993.

PILETTI, N. \& PILETTI, C. História da Educação. São Paulo: Ática, 2000.

PIRES, M. F. de C. Multidisciplinaridade, Interdisciplinaridade e Transdisciplinaridade no Ensino. Interface, Botucatu, v. 2, n. 2, p. 173-18, fev. 1998.

SOUSA SANTOS, B. de. Um discurso sobre as Ciências. São Paulo: Cortez, 2006.

TRAVAGLIA, L. C. Gramática e interação: uma proposta para o ensino de gramática. São Paulo: Cortez, 2009. 
TRINDADE, S. A. \& MENEZES, I. R. A educação na modernidade e a modernização da escola no Brasil: século XIX e início do século XX. Revista HISTEDBR On-line, Campinas, n.36, p. 124-135, dez. 2009.

UFABC. Universidade Federal do ABC. Projeto Pedagógico. Versão original, fevereiro de 2006.

<http://www.ufabc.edu.br/images/stories/pdfs/institucional/projetopedagogico.pdf $>$.

Acesso em 05 de janeiro de 2016.

ZYLBERSZTAJN, A. Galileu: um cientista e várias visões. Caderno Catarinense de Ensino de Física, v.5, n. Especial, p. 36-48, jun. 1988.

Recebido em: 16.10 .2018

Aceito em: 07.01.2019 